\title{
Analysis of factors affecting endocrine therapy resistance in breast cancer
}

\author{
MIN ZHANG ${ }^{1}$, HUI CHEN ${ }^{2}$ and $\mathrm{JUN} \mathrm{GU}^{2}$ \\ ${ }^{1}$ Department of Mastopathy, Nanjing Maternity and Child Health Care Hospital, Nanjing, Jiangsu 210000; \\ ${ }^{2}$ Department of General Surgery, Jinling Hospital, Medical School of Nanjing University, Nanjing, Jiangsu 210002, P.R. China
}

Received October 25, 2014; Accepted August 20, 2015

DOI: 10.3892/ol.2015.3887

\begin{abstract}
The present study aimed to identify the factors involved in the resistance to endocrine therapy in breast cancer (BC) patients with a positive estrogen receptor status via the collection of clinical, pathological and immunohistochemical indices. A retrospective survey was performed in patients who experienced the relapse and metastasis of $\mathrm{BC}$ between November 2007 and March 2013. A total of 45 patients were enrolled, and the observational duration was 7-84 months. The Kaplan-Meier method was used to create a survival curve, while the log-rank test was used to analyze the survival curve and the Cox regression analysis was used to investigate the associated factors contributing to the resistance to endocrine therapy. Univariate analysis showed that the age of onset, the use of radiotherapy, the endocrine treatment program, and the expression levels of progesterone receptor (PR) and CerbB2 affected the impact of endocrine treatment. The Cox regression analysis indicated that the age of onset, the use of radiotherapy, and the expression levels of PR and CerbB2 affected the disease-free survival time after endocrine therapy. A young age of onset, not receiving radiotherapy, a low expression level of $\mathrm{PR}$ and a high expression level of CerbB2 were the risk factors involved in the resistance to endocrine therapy in patients with $\mathrm{BC}$.
\end{abstract}

\section{Introduction}

Breast cancer (BC) is a common malignancy that is a serious threat to the health of women. It has been reported that $\sim 1.5$ million women are diagnosed with $\mathrm{BC}$ annually in the world and that nearly 0.5 million succumb to this disease (1). With accumulating studies on BC, the therapeutic schemes for BC have become much more mature, evolving from the initial local excision to current surgery-based comprehensive treatments,

Correspondence to: Dr Jun Gu, Department of General Surgery, Jinling Hospital, Medical School of Nanjing University, 305 East Zhongshan Road, Nanjing, Jiangsu 210002, P.R. China

E-mail: jungucn@126.com

Key words: breast cancer, endocrine therapy, estrogen receptor, endocrine therapy resistance including radiotherapy, chemotherapy, endocrine therapy, biological immune therapy and molecular-targeted therapy.

The estrogen receptor (ER) is often found in BC and this cancer is consequently labeled as ER-positive (ERP). Furthermore, as the occurrence and development of $\mathrm{BC}$ is so closely associated with the expression of the ER (2), endocrine therapy has been widely used as an effective therapeutic method. In the past few decades, endocrine therapeutic drugs have significantly improved the clinical outcomes of BC patients, as well as their quality of life $(3,4)$. Recently, two multi-center, large-scale, prospective clinical trials further established the positive effect of endocrine therapy in BC treatment $(5,6)$.

However, with the extension of endocrine treatment, certain studies found that a few BC patients showed resistance to endocrine therapy. The clinical data indicated that although there were BC-ERP patients who were suitable for endocrine therapy, $\sim 30 \%$ of BC-ERP patients exhibited resistance to endocrine drugs in the early stages of treatment (primary resistance), and $\sim 40 \%$ BC-ERP of patients showed the effectiveness of endocrine therapy prior to exhibiting gradually reduced sensitivity or resistance with the extension of treatment time $(7,8)$. This ERP status greatly affected the clinical efficacy, and even lead to the failure of clinical BC treatment. Recently, certain studies reported that ERP may be associated with the following factors: Certain receptors, such as human epidermal growth factor-2, insulin-like growth factor receptor and fibroblast growth factor receptor, the phosphoinositide 3-kinase-Akt signal pathway and the abnormal expression of associated microRNAs (9-15). However, these studies did not take the clinical factors into consideration. Therefore the present study analyzed 45 patients who experienced the relapse and metastasis of BC between November 2007 and March 2013, and attempted to identify the clinical factors that were involved in the resistance to endocrine therapy.

\section{Materials and methods}

Subjects. BC patients who were treated in the Department of General Surgery, Jinling Hospital, Medical School of Nanjing University (Nanjing, Jiangsu, China) between November 2007 and March 2013 were enrolled in the study. The inclusion criteria were as follows: i) No metastasis when initially treated; ii) positive ER immunohistochemical results; iii) receipt of endocrine therapy; iv) metastasis or recurrence occurring 
Table I. Baseline patient demographics and clinical characteristics.

\begin{tabular}{|c|c|c|c|c|}
\hline Index & Frequency, n & Ratio, \% & Effective ratio, $\%$ & Accumulated ratio, $\%$ \\
\hline \multicolumn{5}{|l|}{ Age, years } \\
\hline$\leq 50$ & 27 & 60.0 & 60.0 & 60.0 \\
\hline$>50$ & 18 & 40.0 & 40.0 & 100.0 \\
\hline \multicolumn{5}{|l|}{ Menstrual status at onset } \\
\hline Menostasis at onset & 32 & 71.1 & 71.1 & 71.1 \\
\hline No menostasis at onset & 13 & 28.9 & 28.9 & 100.0 \\
\hline \multicolumn{5}{|l|}{ Staging } \\
\hline II & 22 & 48.9 & 48.9 & 48.9 \\
\hline III & 21 & 46.7 & 46.7 & 95.6 \\
\hline Unclear & 2 & 4.4 & 4.4 & 100.0 \\
\hline \multicolumn{5}{|l|}{ Radiotherapy } \\
\hline No & 25 & 55.6 & 55.6 & 55.6 \\
\hline Yes & 20 & 44.4 & 44.4 & 100.0 \\
\hline \multicolumn{5}{|l|}{ PR } \\
\hline- & 12 & 26.7 & 26.7 & 26.7 \\
\hline+ & 33 & 73.3 & 73.3 & 100.0 \\
\hline \multicolumn{5}{|l|}{ CerbB2 } \\
\hline - and + & 31 & 68.9 & 68.9 & 68.9 \\
\hline++ and +++ & 14 & 31.1 & 31.1 & 100.0 \\
\hline \multicolumn{5}{|l|}{ Endocrine therapy } \\
\hline Tamoxifen & 34 & 75.6 & 75.6 & 75.6 \\
\hline Aromatizing enzyme inhibitor & 11 & 24.4 & 24.4 & 100.0 \\
\hline
\end{tabular}

PR, progesterone receptor.

following endocrine therapy; and v) complete clinical and retrospective follow-up data. This study was conducted in accordance with the Declaration of Helsinki. This study was conducted with approval from the Ethics Committee of Jinling Hospital, Medical School of Nanjing University. Written informed consent was obtained from all participants.

Research methods. A retrospective survey was performed in the $45 \mathrm{BC}$ patients that met the inclusion criteria. The basic information, relevant test results and survival information were collected, including the age of onset, menstrual status at onset, pathological and lymph node status, immunohistochemistry, radiotherapy, endocrine therapy drugs and disease-free survival time. The cut-off for PR positivity was immunohistochemical staining in $\geq 10 \%$ of tumor cells. The scoring of CerbB2 by immunohistochemical was: -, no membrane staining; +, weak and incomplete membrane staining, ++ , strong, complete membrane staining in $\leq 30 \%$ of tumor cells or weak/moderate heterogeneous complete membrane staining in $\geq 10 \%$ of tumor cells; or +++ , strong, complete, homogeneous membrane staining in $>30 \%$ of tumor cells. Outcome indices included the recurrence or metastasis of $\mathrm{BC}$, and the follow-up time was 7-120 months. The local recurrence was confirmed by pathological diagnosis, and the sites of distant metastasis were determined by examinations such as ultrasound, X-ray, bone scan, computed tomography, magnetic resonance imagining or positron emission tomography. The disease-free survival time was calculated from the date of diagnosis to the date of recurrence.

Statistical analysis. The measurement data in this study were expressed as the mean \pm standard deviation, and the counting data were expressed as rates. The Kaplan-Meier method was used to create the survival curve, the log-rank test was used to compare the disease-free survival rate and the Cox regression analysis was used to investigate the associated factors that affected the survival time. SPSS 19.0 statistical software (SPSS Inc., Chicago, IL, USA) was used for the statistical analysis. All statistical tests were two-sided, and statistical significance was defined as $\mathrm{P}<0.05$.

\section{Results}

Basic data. A total of $45 \mathrm{BC}$ cases were enrolled into this study, with a minimum age of 27 years old, a maximum age of 87 years old and an average age of $46.76 \pm 11.89$ years old. The median disease-free survival time was 31 months. The remaining basic data are shown in Table I.

Single factor analysis of effects of different clinical indicators on endocrine resistance. The disease-free survival times were observed with regard to the age of onset, menstrual status at onset, BC staging, chemotherapy status, endocrine therapy and different levels of PR and CerbB2, and then survival curves 
Table II. Univariate Cox regression analysis.

\begin{tabular}{|c|c|c|c|c|c|c|c|}
\hline \multirow[b]{2}{*}{ Index } & \multirow[b]{2}{*}{ B } & \multirow[b]{2}{*}{ SE } & \multirow[b]{2}{*}{ Index } & \multirow[b]{2}{*}{ P-value } & \multirow[b]{2}{*}{$\mathrm{RR}$} & \multicolumn{2}{|c|}{$95 \% \mathrm{CI}$} \\
\hline & & & & & & $\begin{array}{l}\text { Lower } \\
\text { limit }\end{array}$ & $\begin{array}{c}\text { Upper } \\
\text { limit }\end{array}$ \\
\hline Age of onset & -0.860 & 0.369 & 5.430 & $0.020^{\mathrm{a}}$ & 0.423 & 0.205 & 0.872 \\
\hline Menstrual status at onset & -0.036 & 0.332 & 0.012 & 0.913 & 0.965 & 0.503 & 1.849 \\
\hline Staging & -0.265 & 0.327 & 0.658 & 0.417 & 0.767 & 0.404 & 1.456 \\
\hline Radiotherapy & -1.085 & 0.350 & 9.629 & $0.002^{\mathrm{a}}$ & 0.338 & 0.170 & 0.671 \\
\hline Endocrine therapy & 0.990 & 0.368 & 7.220 & $0.007^{\mathrm{b}}$ & 2.692 & 1.307 & 5.542 \\
\hline PR expression & -0.832 & 0.363 & 5.234 & $0.022^{\mathrm{a}}$ & 0.435 & 0.214 & 0.888 \\
\hline CerbB2 expression & -0.502 & 0.140 & 2.124 & $0.017^{\mathrm{a}}$ & 0.605 & 0.460 & 0.796 \\
\hline
\end{tabular}

${ }^{\mathrm{a}} \mathrm{P}<0.05 ;{ }^{\text {b }} \mathrm{P}<0.01$. CI, confidence interval; $\mathrm{RR}$, risk ratio; $\mathrm{PR}$, progesterone receptor; $\mathrm{SE}$, standard error.

Table III. Model test of Cox regression.

\begin{tabular}{lc}
\hline Parameter & Value \\
\hline 2-fold logarithm likelihood value & 203.737 \\
$\chi^{2}$ & 30.42 \\
Degrees of freedom & 9 \\
P-value & $<0.0001$
\end{tabular}

were created. It was demonstrated that patients with an age of onset of $>50$ years, stage II disease, radiotherapy, $\mathrm{PR}(+)$ and CerbB2 (- and +$)$ showed a higher incidence of resistance to endocrine therapy (Fig. 1).

Cox univariate regression analysis. The disease-free survival time, recurrence and metastasis were set as the dependent variables. By contrast, the age of onset, menopausal status at onset, lymph node status, clinical staging, radiotherapy, endocrine therapy, PR expression and CerbB2 expression were set as the independent variables for the Cox univariate regression analysis. The results revealed that the age of onset, radiotherapy, endocrine therapy, PR expression and CerbB2 expression exhibited an impact on the disease-free survival time (Table II).

Coxmultivariate regression analysis. The disease-free survival time, recurrence and metastasis were set as the dependent variables. Those clinical indicators that had statistical significance in the Cox univariate regression analysis, namely the age of onset, radiotherapy, endocrine therapy, PR expression and CerbB2 expression, were set as the independent variables for the Cox regression with the Enter method. The model testing results indicated that the model had statistical significance (Table III). The Cox regression analysis showed that the different ages of onset exhibited a statistical significant effect on the endocrine therapy ( $\mathrm{P}=0.019)$, with a standardized odds ratio (OR) value of 3.658 and a $95 \%$ confidence interval $(\mathrm{CI})$ of 1.235-10.836. Different radiotherapies also exhibited statistical significance $(\mathrm{P}=0.006)$, with a standardized $\mathrm{OR}$ value of 2.838 and a $95 \%$ CI of 1.342-6.000. Different expression levels of PR also exhibited statistical significance $(\mathrm{P}=0.002)$, with a standardized OR value of 2.631 and a $95 \%$ CI of 1.416-4.889. Furthermore, different expression levels of CerbB2 exhibited statistical significance $(\mathrm{P}=0.043)$, with a standardized OR value of 2.631 and a $95 \%$ CI of 1.416-4.889. The Cox multivariate regression analysis showed that the different ages of onset, the use of pre-operative radiotherapy, and the different expression levels of PR and CerbB2 exhibited statistical significance with regard to the post-endocrine-therapy disease-free survival time, which indicated that these factors may affect the endocrine therapy resistance of BC (Table IV).

\section{Discussion}

Currently, endocrine therapy is an important part of comprehensive BC treatment (16). Although molecular typing and screening in recent years have provided an effective method for choosing the most sensitive candidates for endocrine therapy, a considerable number of patients exist that are not sensitive to endocrine therapy $(17,18)$. Therefore, further investigation of the specific indicators is necessary for improving the efficacy of endocrine treatment. The present study aimed to search for novel indicators for screening the sensitive populations and predicting the efficacy of the treatment.

Considering the close association between ER and BC, the sensitivity to endocrine therapy in patients with different levels of ER was first analyzed. The ATAC trial compared the efficacy of tamoxifen (TAM) and anastrozole, from which one result showed that the recurrence rate of $\mathrm{ER}^{+} / \mathrm{PR}^{-}$patients was significantly higher than that of $\mathrm{ER}^{+} / \mathrm{PR}^{+}$patients. Due to the different PR status, this cancer could not simply be referred to as receptor-positive BC. In 2007, experts in the St. Gallen conference came to the consensus that $\mathrm{ER}^{+} / \mathrm{PR}^{-}$was included in the endocrine incomplete reaction type (19). Arpino et al (20) reported that $70 \%$ of $\mathrm{BC}$ patients with double-positive ER and PR were sensitive to endocrine therapy, while only $34 \%$ of $\mathrm{ER}^{+} / \mathrm{PR}^{-} \mathrm{BC}$ patients were sensitive to endocrine therapy. This data confirmed that besides ER, PR also played an important role in forecasting the efficacy of endocrine therapy. In $\mathrm{ER}^{+}$ $\mathrm{BC}$ patients, $\mathrm{PR}^{-}$patients were more prone to generating TAM resistance than the $\mathrm{PR}^{+}$patients, therefore leading to treatment 
Table IV. Multivariate Cox regression analysis.

\begin{tabular}{lcccccrr}
\hline & & & & & & & \multicolumn{2}{c}{$95 \% \mathrm{CI}$} \\
\cline { 5 - 8 } Index & $\begin{array}{c}\text { Estimate } \\
\text { value }\end{array}$ & $\mathrm{SD}$ & Wald & P-value & $\begin{array}{c}\text { Standardized } \\
\text { estimated value }\end{array}$ & $\begin{array}{c}\text { Lower } \\
\text { limit }\end{array}$ & $\begin{array}{r}\text { Upper } \\
\text { limit }\end{array}$ \\
\hline Age of onset & 1.297 & 0.554 & 5.488 & $0.019^{\mathrm{a}}$ & 3.658 & 1.235 & 10.836 \\
Staging & 0.090 & 0.484 & 0.035 & 0.853 & 1.094 & 0.424 & 2.822 \\
Radiotherapy & 1.043 & 0.382 & 7.439 & $0.006^{\mathrm{b}}$ & 2.838 & 1.342 & 6.000 \\
Endocrine therapy & 0.762 & 0.457 & 2.785 & 0.095 & 2.142 & 0.875 & 5.243 \\
PR expression & 0.967 & 0.316 & 9.371 & $0.002^{\mathrm{b}}$ & 2.631 & 1.416 & 4.889 \\
CerbB2 expression & -0.961 & 0.476 & 4.077 & $0.043^{\mathrm{a}}$ & 0.382 & 0.150 & 0.972
\end{tabular}

${ }^{\mathrm{a}} \mathrm{P}<0.05 ;{ }^{\mathrm{b}} \mathrm{P}<0.01$. CI, confidence interval; $\mathrm{SD}$, standard deviation; $\mathrm{PR}$, progesterone receptor.

A

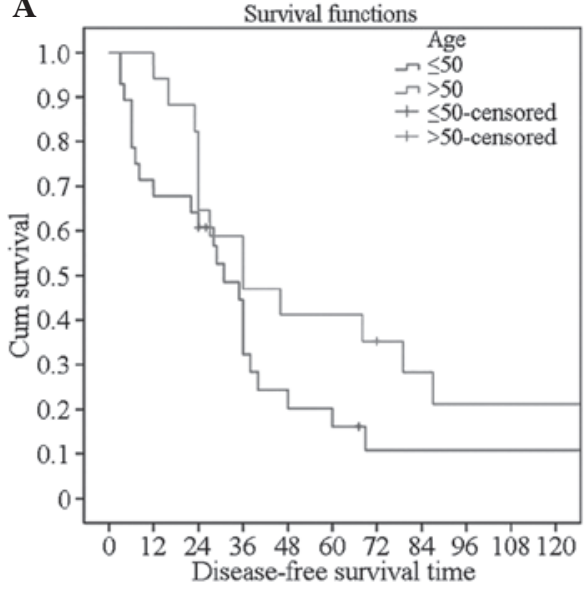

B

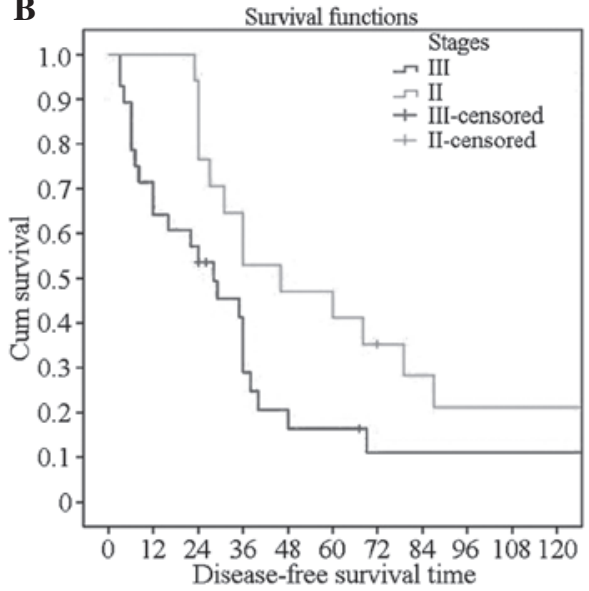

$\mathbf{C}$

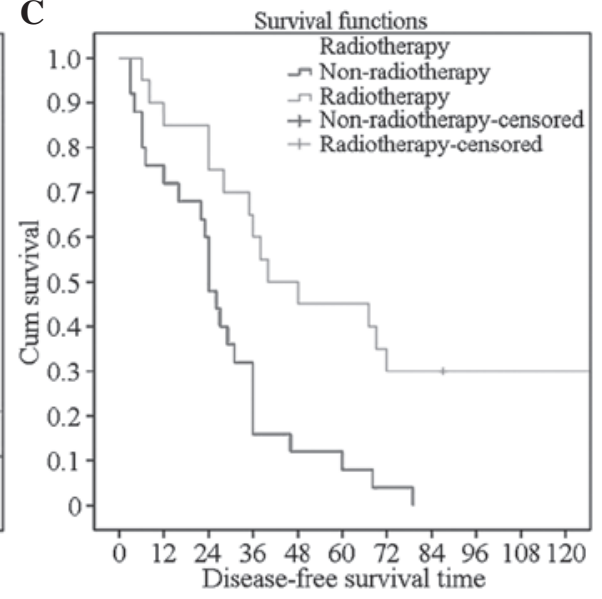

D

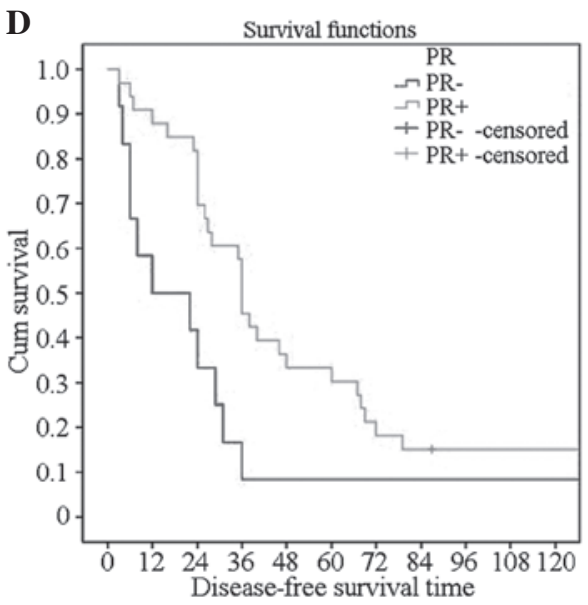

$\mathbf{E}$

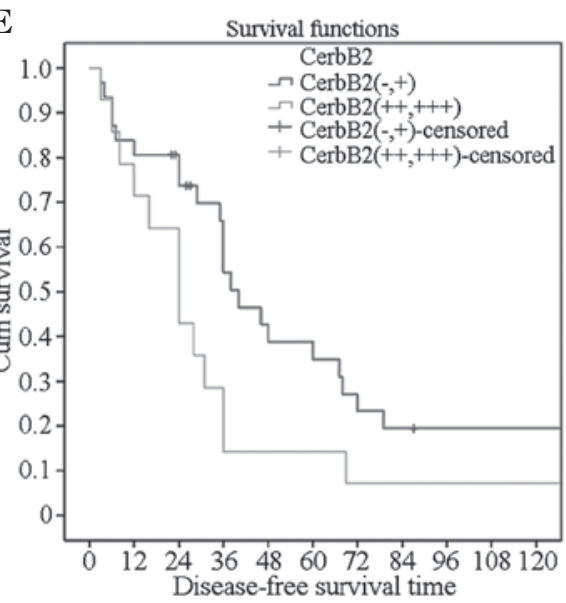

Figure 1. (A) Association between cumulative survival rate and age of onset; (B) association between cumulative survival rate and clinical stage; (C) association between cumulative survival rate and radiotherapy; (D) association between cumulative survival rate and progesterone receptor (PR) status; and (E) association between cumulative survival rate and CerbB2 status.

failure (21). In the present study, the Cox multivariate regression analysis showed that the treatment efficacy of $\mathrm{ER}^{+} / \mathrm{PR}^{+} \mathrm{BC}$ patients was significantly better than those who were $\mathrm{ER}^{+} / \mathrm{PR}^{-}$, which was consistent with other studies. Nicholson et al (22) first reported that the efficacy of TAM towards metastatic BC patients with CerbB2 overexpression was decreased from 38 to $7 \%$ compared with those with no CerbB2; Wright et al (23) also showed that high CerbB2 expression made the response of $\mathrm{ER}^{+} \mathrm{BC}$ patients towards TAM decrease from 48 to $20 \%$. Meng et al (24) considered that the higher the expression level of CerbB2 the quicker the progress of $\mathrm{BC}$ metastasis or recurrence, and suggested that the overall disease-free survival time would also be short, all represented as the different levels of endocrine therapy resistance. In the present study, the Cox multivariate 
regression analysis showed that the risk of endocrine resistance in the patients with high CerbB2 expression $(++$ and +++$)$ was higher than that in those with low or no expression of CerbB2 $(-$ and +$)$. This was also basically consistent with the results of the study by Gregory et al (25).

The present results also indicated that certain clinical parameters may predict the sensitivity of endocrine therapy. According to the Cox multivariate regression analysis, patients $>50$ years old at onset was less sensitive to endocrine therapy than those $\leq 50$ years old. This may be as the degree of malignancy in the young $\mathrm{BC}$ patients was higher, with a more aggressive nature, which would be more prone to relapse and metastasis; while the elder BC patients exhibited slow progression, with a prognosis that was relatively improved. Although $\mathrm{BC}$ is a hormone-dependent tumor, the present study found that menopause exhibited no significant effect on endocrine therapy resistance. This conclusion was inconsistent with some previous studies (26). A small sample size, selection criteria and different age-division ranges may also contribute to this conclusion. The application of BC chemotherapeutic drugs reduced the risk of $\mathrm{BC}$ recurrence and metastasis, and prolonged the survival time. No studies exist to confirm the impact of radiotherapy on endocrine therapy resistance, however, in the present study, radiotherapy had a positive impact, which probably resulted from the small sample size and requires future large-scale clinical trials for further verification.

The aromatase inhibitors (AIs) were effective towards the TAM-resistant BC, and have been approved as a second-line drug against postmenopausal metastatic BC (27). The 91-month follow-up data for IES031 showed that compared with TAM, exemestane significantly improved disease-free survival, and reduced the risks of local and distant recurrence, while significantly increasing the overall survival rate of $\mathrm{ER}^{+}$patients for unknown reasons. The results of a 2.75-year follow-up by TEAM also showed that, compared with TAM, exemestane significantly reduced the risks of recurrence and distant metastasis (28). A clinical study (29) showed that with regard to the postmenopausal BC patients, when TAM treatment generated resistance, the application of second-line drugs (AIs) would still be effective. A total of $30 \%$ of the BC patients who were resistant to the AI therapy could obtain a clinical benefit from fulvestrant treatment, which also indicated that selective estrogen receptor modulators would play a role against the AI-resistant cells. Therefore, the sequential or combined application of endocrine therapy drugs could avoid endocrine therapy resistance to a certain extent. In the present study, univariate Cox regression analysis demonstrated that the patients receiving tamoxifen exhibited a significantly improved disease-free survival rate compared with those receiving AIs, however, the difference was not observed in the multivariate Cox model. Upon review of the clinical data, aside from the small sample size, the results were also impacted by the fact that among the $45 \mathrm{BC}$ patients, 6 patients did not experience relapse or metastasis within 10 years. Of these patients, 5 were administrated TAM, and among these 5, 1 patient underwent a modified radical mastectomy combined with bilateral oophorectomy and 1 patient underwent a uterine adnexectomy for other gynecological disease prior to $\mathrm{BC}$ diagnosis. Therefore, the gynecological surgeries affected the endocrine status, which may have had a greater impact on the results.
Taken together, the present study demonstrated that certain clinicopathological parameters, including younger age of onset, not receiving radiotherapy, a low expression level of PR and a high expression level of CerbB2, may be risk factors that contribute to tamoxifen or AIs resistance. Hence, patients with these characteristics should be cautiously supervised during endocrine therapy.

\section{References}

1. de Martel C, Ferlay J, Franceschi S, Vignat J, Bray F, Forman D and Plummer M: Global burden of cancers attributable to infections in 2008: A review and synthetic analysis. Lancet Oncol 13: 607-615, 2012

2. Oliveras-Ferraros C, Vazquez-Martin A, Cufí S, Torres-Garcia VZ, Sauri-Nadal T, Barco SD, Lopez-Bonet E, Brunet J, Martin-Castillo B and Menendez JA: Inhibitor of Apoptosis (IAP) survivin is indispensable for survival of HER2 gene-amplified breast cancer cells with primary resistance to HER1/2-targeted therapies. Biochem Biophys Res Commun 407: 412-419, 2011.

3. Regan MM, Neven P, Giobbie-Hurder A, Goldhirsch A, Ejlertsen B, Mauriac L, Forbes JF, Smith I, Láng I, Wardley A, et al: Assessment of letrozole and tamoxifen alone and in sequence for postmenopausal women with steroid hormone receptor-positive breast cancer: The BIG 1-98 randomised clinical trial at 8.1 years median follow-up. Lancet Oncol 12: 1101-1108, 2011.

4. Bliss JM, Kilburn LS, Coleman RE, Forbes JF, Coates AS, Jones SE, Jassem J, Delozier T, Andersen J, Paridaens R, et al: Disease-related outcomes with long-term follow-up: An updated analysis of the intergroup exemestane study. J Clin Oncol 30: 709-717, 2012.

5. Davies C, Pan H, Godwin J, Gray R, Arriagada R, Raina V, Abraham M, Medeiros Alencar VH, Badran A, Bonfill X, et al: Long-term effects of continuing adjuvant tamoxifen to 10 years versus stopping at 5 years after diagnosis of oestrogen receptor-positive Breast cancer: ATLAS, a randomised trial. Lancet 381: 805-816, 2013.

6. Burstein HJ, Temin S, Anderson H, Buchholz TA, Davidson NE, Gelmon KE, Giordano SH, Hudis CA, Rowden D, Solky AJ, et al: Adjuvant endocrine therapy for women with hormone receptor-positive breast cancer: American society of clinical oncology clinical practice guideline focused update. J Clin Oncol 32: 2255-2269, 2014.

7. Traub F, Feist H, Kreipe HH and Pich A: SELDI-MS-based expression profiling of ductal invasive and lobular invasive human Breast carcinomas. Patholo Res Pract 201: 763-770, 2005.

8. Caldon CE, Sergio CM, Kang J, Muthukaruppan A, Boersma MN, Stone A, Barraclough J, Lee CS, Black MA, Miller LD, et al: Cyclin E2 overexpression is associated with endocrine resistance but not insensitivity to CDK2 inhibition in human Breast cancer cells. Mol Cancer Ther 11: 1488-1499, 2012.

9. Osborne CK and Schiff R: Mechanisms of endocrine resistance in breast cancer. Annu Rev Med 62: 233-247, 2011.

10. Garcia-Becerra R, Santos N, Diaz L and Camacho J: Mechanisms of resistance to endocrine therapy in breast cancer: Focus on signaling pathways, miRNAs and genetically based resistance. Int J Mol Sci 14: 108-145, 2012.

11. O'Hara J, Vareslija D, McBryan J, Bane F, Tibbitts P, Byrne C, Conroy RM, Hao Y, Gaora PÓ, Hill AD, et al: AIB1: ERa transcriptional activity is selectively enhanced in aromatase inhibitor-resistant breast cancer cells. Clin Cancer Res 18: 3305-3315, 2012.

12. Hawsawi Y, El-Gendy R, Twelves C, Speirs V and Beattie J: Insulin-like growth factor-oestradiol crosstalk and mammary gland tumourigenesis. Biochim Biophys Acta 1836: 345-353, 2013.

13. Hasson SP, Rubinek T, Ryvo L and Wolf I: Endocrine resistance in breast cancer: Focus on the phosphatidylinositol 3-kinase/akt/mammalian target of rapamycin signaling pathway. Breast Care (Basel) 8: 248-255, 2013.

14. Rao X, Di Leva G, Li M, Fang F, Devlin C, Hartman-Frey C, Burow ME, Ivan $M$, Croce $C M$ and Nephew KP: MicroRNA-221/222 confers breast cancer fulvestrant resistance by regulating multiple signaling pathways. Oncogene 30: 1082-1097, 2011 
15. Ward A, Shukla K, Balwierz A, König R, Sahin O and Wiemann S: MicroRNA-519a is a novel oncomir conferring tamoxifen resistance by targeting a network of tumour-suppressor genes in ER+ breast cancer. J Pathol 233: 368-379, 2014.

16. Zelnak AB and O'Regan RM: Optimizing endocrine therapy for breast cancer. J Natl Compr Canc Netw 13: e56-64, 2015.

17. Regan MM: Predicting benefit of endocrine therapy for early breast cancer. Breast S0960-9776: 00167-00168, 2015.

18. Feng Q, Zhang Z, Shea MJ, Creighton CJ, Coarfa C, Hilsenbeck SG, Lanz R, He B, Wang L, Fu X, et al: An epigenomic approach to therapy for tamoxifen-resistant breast cancer. Cell Res 24: 809-819, 2014.

19. Goss PE, Ingle JN, Martino S, Robert NJ, Muss HB, Piccart MJ, Castiglione M, Tu D, Shepherd LE, Pritchard KI et al, National Cancer Institute of Canada Clinical Trials Group MA.17: Efficacy of letrozole extended adjuvant therapy according to estrogen receptor and progesterone receptor status of the primary tumor: National Cancer Institute of Canada Clinical Trials Group MA.17. J Clin Oncol 25: 2006-2011, 2007.

20. Arpino G, Weiss H, Lee AV, Schiff R, De Placido S, Osborne CK and Elledge RM: Estrogen receptor-positive, progesterone receptor-negative breast cancer: Association with growth factor receptor expression and tamoxifen resistance. J Natl Cancer Inst 97: 1254-1261, 2005.

21. Richer JK, Jacobsen BM, Manning NG, Abel MG, Wolf DM and Horwitz KB: Differential gene regulation by the two progesterone receptor isoforms in human breast cancer cells. J Biol Chem 277: 5209-5218, 2002.

22. Nicholson RI and Johnston SR: Endocrine therapy--current benefits and limitations. Breast Cancer Res Treat 93: S3-10, 2005
23. Wright C, Nicholson S, Angus B, et al.: Relationship between c-erbB-2 protein product expression and response to endocrine therapy in advanced breast cancer. Br J Cancer 65: 118-121, 1992.

24. Meng S, Tripathy D, Shete S, Ashfaq R, Haley B, Perkins S, Beitsch P, Khan A, Euhus D, Osborne C, et al: HER-2 gene amplification can be acquired as breast cancer progresses. Proc Natl Acad Sci USA 101: 9393-9398, 2004.

25. Gregory RK, Powles TJ, Salter J, Chang JC, Ashley S and Dowsett M: Prognostic relevance of cerbB2 expression following neoadjuvant chemotherapy in patients in a randomised trial of neoadjuvant versus adjuvant chemoendocrine therapy. Breast Cancer Res Treat 59: 171-175, 2000.

26. Fan P, Yue W, Wang JP, Aiyar S, Li Y, Kim TH and Santen RJ: Mechanisms of resistance to structurally diverse antiestrogens differ under premenopausal and postmenopausal conditions: Evidence from in vitro breast cancer cell models. Endocrinology 150: 2036-2045, 2009.

27. Bliss JM1, Kilburn LS, Coleman RE, Forbes JF, Coates AS, Jones SE, Jassem J, Delozier T, Andersen J, Paridaens R, et al: Disease-related outcomes with long-term follow-up: An updated analysis of the intergroup exemestane study. J Clin Oncol 30: 709-717, 2012.

28. van de Velde CJ, Rea D, Seynaeve C, Putter H, Hasenburg A, Vannetzel JM, Paridaens R, Markopoulos C, Hozumi Y, Hille ET, et al: Adjuvant tamoxifen and exemestane in early breast cancer (TEAM): a randomised phase 3 trial. Lancet 377: 321-331, 2011.

29. Jha K, Shukla M and Pandey M: Survivin expression and targeting in breast cancer. Surg Oncol 21: 125-131, 2012. 